\title{
Executive Functions in Cannabis Users: A Comparative Study
}

\author{
Sushma Rathee*
}

Ph. D., M. Phil (Clinical Psychology), Assistant Clinical Psychologist, Psychiatry Department, PGIMER, Chandigarh, India

*Corresponding author: Rathee S, Ph. D., M. Phil (Clinical Psychology), Assistant Clinical Psychologist, Psychiatry Department, PGIMER, Chandigarh, India, Tel: 0172274 7585; E-mail: sushmaratheecp@gmail.com

Received: January 29, 2021; Accepted: April 01, 2021; Published: April 13, 2021

\begin{abstract}
Background: Cannabis is a recreational drug which is used in worldwide despite banned in some areas. It has to influence the effect on our executive functions either improving or damaging. In the research area, there is still a dispute about the adverse effect of this drug on executive functions.

Aim: To examine the variation in executive functions of persistent and causal users of cannabis, abstainers, and healthy control.

Method: Two hundred seventy cannabis users (of equal number in various group, i.e., persistent cannabis users, casual cannabis users \& abstainers) and ninety healthy participants ( $N=360)$ from four states of India i.e., Haryana, Punjab, Rajasthan, and Chandigarh.

Tools: Socioeconomic Status Scale, Stoop Neuropsychological Test, and Wisconsin Card Sorting Test were administered for attaining the objective of the present study.

Results and Discussion: In the results, it has been found that persistent users had highest deficits in the executive functions which were measured with the help of Stroop task and Wisconsin Card Sorting Test, persistent users had poor performance on error response, preservative response, preservative error, and conceptual error. Whereas results also showed that abstainers group had the more or less equal performance to healthy control and better than casual and persistent users on cognitive functions.

Conclusion: Results of the study suggests that the use of cannabis is associated with deficits in process of the brain, response inhibition, decision making, maintaining the mental set, learning the new concept etc.
\end{abstract}

Keywords: Executive functions; Cannabis use; Persistent users; Cognitive functions

Key Message: Cannabis use has significant impact on the process of brain. It could be negative or positive, which is more or less depends on the few factors such as age of the use, amount and frequency. There are so many symptoms has been found after use and specifically in the study it has been found that after use of cannabis for long time there is significant change has been noticed in the higher executive functions.

Abbreviations: $\mathrm{C}$ responses: Correct responses; \%E responses: percent Error responses; \% P responses: percent Preservative Responses; \%P errors: percent Preservative Errors; \%N-P errors: percent Non- Preservative Errors; \%CLR: percent Conceptual

Citation: Rathee S. Executive Functions in Cannabis Users: A Comparative Study. J Anxiety Depress. 2021;4(1):134. 
www.yumedtext.com | April-2021 | ISSN: 2582-3264 | https://dx.doi.org/10.46527/2582-3264.134

Level Responses; NOCC $=$ Number of Category Completed; TTCFC: Total Trial to Completed in First Category; FTMS: Failure to Maintain Set; LL: Learning to Learn; BSS: Between Group; WSS: Within Group; SS: Sum of Squares; MS: Mean Square; NS: non-significant

\section{Introduction}

Executive function is the ability of human beings, to behave and adapt smartly and effectively in every situation either simple or complex. It requires different types of cognitive functions that make an individual different from others. It is possible only through the spread, growth, or development of the human brain, mainly the prefrontal cortex. These functions include basic as well as higher levels of cognitive processes, such as attentional control, cognitive inhibition, inhibitory control, working memory, and cognitive flexibility. These required uses of fluid intelligence [1-3]. Now a day's life is fast-paced, competitive and stressful. It is generally assumed that stress and other hazards are playing a key role in disrupting the highest level of cognitive functions. There are so many examples of our daily life where we forget much of our important information only because of overloaded or distress and many times unable to take a decision within the time. These functions progressively developed and changed the whole life of a person and these can be enhanced at any time of a person's life [2].

The prefrontal cortex is necessary and an important brain region in regulating the executive functions, but this is also true that it is not solely sufficient for executive functions $[2,4,1]$ for example, there is some other brain also found, which is related to these functions known as; the caudate nucleus and sub-thalamic nucleus [1].

In some studies, overall global cognition and executive functions were found impaired in cannabis users [5-7]. Ramaekers et al.,[8] reported significant negative effects of the use of cannabis on executive functions, impulse control, attention, and psychomotor functions. Raul et al.,[9] revealed that cannabis-impaired decision-making and episodic memory and enhance risk-taking behaviour. Ramaekers et al.,[10] found that potency of cannabis exposure impaired the decision making and increased the reaction time and also impaired the executive functions.

Similarly, Krista et al.,[11] reported that cannabis exposure was associated with poor psychomotor performance, sustained attention and cognitive inhibition. There are studies where is no significant adverse effect was observed in the area of response inhibition, spatial working memory, short term memory, and sustained attention [12,13], and cognitive flexibility [14]. Hartman and Huestis [15] revealed that after exposure of cannabis participants slowdown in driving and deterioration increased with the level of task complexity. Bartholomew, Holroyad, and Hefferman [16], reported another effective variable i.e., awareness of the illness and its harmful effect on the brain. In his study, they found that participants reported no effect of cannabis on their cognition subjectively but objectively they were not able to perform well on the memory task.

There is a gap between the findings of the various studies from the literature. Some studies found an adverse effect of cannabis on executive functions, whereas some showed no effect or enhancing effect of cannabis use. Thus, the present study was planned to examine the variations in executive functions of persistent and causal cannabis users, abstainers, and healthy control.

\section{Objective}

To examine the variations in executive functions of persistent and casual users of cannabis, abstainers, and healthy control. 


\section{Method}

\subsection{Sample}

The present study was conducted on a sample of 360 (Cannabis users $=270, \&$ Healthy Controls=90). The age range was 18 years to 40 years. The clinical sample was selected from drug de-addiction centres from Haryana, Punjab and Rajasthan. In Haryana, the sample was selected from three drug de-addiction treatment hospitals, located in Jind, Panipat and Rohtak. In Punjab sample was selected from four drug de-addiction treatment hospitals, located in Amritsar, Tarn Taran, Jagran, and Barnala, and from Rajasthan sample was selected from drug de-addiction treatment hospital, located in Jaipur. Sample for the present study was selected on the basis of convenience and availability. The healthy control group participants were selected on the basis of purposive sampling and availability of participants from Haryana, Punjab, Rajasthan and Chandigarh. The participants in the clinical and healthy group were matched on age, residence, family type, socio-economic status etc. The data was collected during Oct. 2017 to June 2018.

Design: This is a cross-sectional study.

\subsection{Inclusion Criteria for clinical sample and Exclusion Criteria for clinical sample}

Participants who have a primary diagnosis of cannabis dependence according to ICD-10 criteria. Participants have at least primary level education. Only male participants were selected. 28 days of abstinence period for abstinence for a group of abstainers. One year of persistent use with more than 4 biddi of cannabis per day for persistent cannabis users. Casual users who do not use cannabis regularly and also have an abstinence period in between. For exclusion the following criteria used, participants having primary diagnoses of psychiatric illness, presence of any major medical or neurological illness, participants having multiple substance dependence and refuse to give informed consent.

\subsection{Inclusion Criteria for a healthy sample and Exclusion Criteria for healthy sample}

Participants have at least primary education and were in the age range of 18 to 40 years. Only male participants were selected. Only middle socio-economic status participants were enrolled. On the other hand, participants who have the presence of psychiatric illness or any major medical or neurological illness, any substance dependence and refuse to give informed consent were excluded.

\section{Tools}

Socio-demographic and clinical data sheet: -A socio-demographic record sheet was prepared for collecting the information about various areas of social, demographic and clinical variables. Information relating to age, sex, residence, marital status, education, types of family, occupation, the onset of substance abuse, duration of substance abuse, past psychiatric history, history of multiple substance dependence, family history of psychiatric and substance abuse were recorded in a structured interview setting and the investigator recorded the information.

The following standard psychometric tests were used:

1. Socio-Economic Status Scale: It was developed by Singh, Shyam and Kumar [17]. The scale serves the purpose of categorizing the families in different socio-economic strata. This scale was used for assessing the socio-economic status of the participants. It was developed in Hindi and English for both rural and urban people. In the present study, 
www.yumedtext.com | April-2021 | ISSN: 2582-3264 | https://dx.doi.org/10.46527/2582-3264.134

the Hindi version was used. This scale has test-retest reliability coefficient is 0.653 and internal consistency is 0.791 . Concurrent validity of the scale is reported to be 0.689 . The scoring guidelines are given in the manual. The norms for urban, rural, and mixed are also available.

2. Stroop Neuropsychological Screening Test: This test was developed by Stroop [18-19]. This test is also known as the Color-word Naming Test. This test is applicable for age 15 years to 90 years. It assesses various areas of cognitive functions including cognitive processing, speed of the brain, and also help in the diagnosis of brain dysfunction, cognition and psychopathology. It requires mainly the person to inhibit an automatic response and produce a more effortful colour-naming response. It is also used as an index of response inhibition, cognitive flexibility and analogical reasoning. Test-retest reliability of the test is reported to be 0.90 . Test material consists of Form $\mathrm{C}$ stimulus and response sheet, Form C-W stimulus and response sheet. Both Form C and C-W stimulus sheet consist of 112 items each. In the Form C colour names (Green/हरा, Blue/नीला, Red/लाल, Brown/भूरा) printed in four different colours of ink (Green/हरा, Blue/नीला, Red/लाल, Brown/भूरा), but in the C-W stimulus sheet no single name is printed in its matching colour (e.g., नीला शब्द कही भी नीले रंग में नहीं लिखा हुआ है). The response sheet was used to record the participant's demographic and clinical information and responses for the Color stimulus and Color-Word stimulus tasks. The original Stroop task was translated in the Hindi language so that participants could read easily. For administration of this test, the stopwatch was also used to record the time and participant with stimulus form and experimenter with record form took seats on opposite sides of the table. The Color-Word score is the primary score used in the interpretation. Although many research versions of the Stroop procedure calculate a difference or interference, score based on the performance on the Color and Color-Word Tasks. The Color and Color-Word Scores are calculated by using the following formula: -

$D Q=C-C W \div C \times 100$

$\mathrm{C}=$ Number of correct responses on the Color Task

$\mathrm{CW}=$ Number of correct responses on the Color-Word task

3. Wisconsin Card Sorting Test (WCST): This test was developed Berg [20] to test the process of problem-solving and decision-making. It was also known as a measure of executive function, planning, conceptualization, perseveration, and ability to form abstract concepts. The test can be used for the age range of 6.5 years to 89 years. In this test, the total 128 response card in two sets (64 in each) and 4 stimulus cards administered on the participant. The figures on the cards differ with respect to colour, quantity, and shape. The participant must match the figure, but the examiner did not tell him how to match them, but every time experimenter told him/her that whether the response is right or wrong. The test took approximately 12-20 minutes to Complete. Coefficient of WCST scores based on single test administration ranged from 0.39 to 0.72 . Scoring of the WCST was done as per guidelines of manual.

\section{Procedure}

The sample was selected from various drug-de addiction treatment hospitals of Haryana and Punjab. The participants were assured for the confidentiality of their information as well as their comfort during the testing and also clear them about the purpose of the study. All the participants were recruited only after their written informed consent for testing. After 'Inform 
Consent' from participants an interview session for clinical information was conducted and developed a working therapeutic alliance. After that, the actual administrations of the tests were started, and instructions of all tests were given them. The estimated time for the administration of tests was around 20 to 30 minutes.

\section{Results}

Statistical Analysis: After scoring of responses, the data were analyzed using the SPSS (Statistical Package for the social Sciences) 16.0 version. The data were analyzed by calculating Mean, SD, frequency, Chi-Square, one way ANOVA, followed by Duncan Post hoc test, for significant group comparison.

\section{Discussion}

TABLE 1 shows the frequency and percentage of cases in the persistent, casual users of cannabis, abstainers and controls. The basic purpose was to see if all the groups are almost similar in terms of demographic characteristics. Chi-square was applied to check the significance of the difference. Results (TABLE 1) reveal that all the groups were almost similar in terms of residence (rural, urban and suburban), family type, family history of substance use and psychiatric illness, history of psychiatric illness in past due to cannabis use. The Chi-square values for these are non-significant indicating non-significant variations in the criterion groups in terms of these variables.

TABLE 1. Results of Frequency (Percentage) and Chi Square on demographic variables (Cannabis groups \& Healthy participants).

\begin{tabular}{|c|c|c|c|c|c|c|}
\hline \multirow[t]{2}{*}{ Variables } & \multirow[t]{2}{*}{ Description } & $\begin{array}{r}\text { Persistent } \\
\text { user }(n=90)\end{array}$ & $\begin{array}{c}\text { Casual } \\
\text { user } \\
(\mathrm{n}=90)\end{array}$ & $\begin{array}{l}\text { Abstainers } \\
\qquad(\mathbf{n = 9 0 )}\end{array}$ & $\begin{array}{c}\text { Healthy } \\
\text { Controls } \\
(n=90)\end{array}$ & \multirow[t]{2}{*}{$\begin{array}{c}\text { Chi } \\
\text { Square } \\
\text { value }\end{array}$} \\
\hline & & $\begin{array}{c}\text { Frequency } \\
\text { (Percent) }\end{array}$ & $\begin{array}{c}\text { Frequency } \\
\text { (Percent) }\end{array}$ & $\begin{array}{c}\text { Frequency } \\
\text { (Percent) }\end{array}$ & $\begin{array}{c}\text { Frequency } \\
\text { (Percent) }\end{array}$ & \\
\hline \multirow[t]{3}{*}{ Residence } & Rural & $50(56)$ & $50(56)$ & $48(54)$ & $59(66)$ & \multirow[t]{3}{*}{$4.18^{\mathrm{NS}}$} \\
\hline & Urban & $39(43)$ & $39(43)$ & $40(44)$ & $29(32)$ & \\
\hline & Sub-urban & $1(1)$ & $1(1)$ & $2(2)$ & $2(2)$ & \\
\hline \multirow[t]{2}{*}{ Family Type } & Joint & $46(51)$ & $46(51)$ & $47(52)$ & $36(40)$ & \multirow[t]{2}{*}{$4.02^{\mathrm{NS}}$} \\
\hline & Nuclear & 44 (49) & $44(49)$ & $43(48)$ & $54(60)$ & \\
\hline \multirow{2}{*}{$\begin{array}{c}\text { H/o past } \\
\text { psychiatric } \\
\text { illness in pt. due } \\
\text { to cannabis }\end{array}$} & Present & $7(8)$ & $7(8)$ & $5(6)$ & 0 & \multirow[t]{2}{*}{$0.47^{\mathrm{NS}}$} \\
\hline & Absent & $83(92)$ & $83(92)$ & $85(94)$ & 0 & \\
\hline \multirow{2}{*}{$\begin{array}{l}\text { H/o psychiatric } \\
\text { and substance } \\
\text { abuse illness in } \\
\text { family }\end{array}$} & Present & $31(34)$ & $34(38)$ & $36(40)$ & 0 & \multirow[t]{2}{*}{$0.58^{\mathrm{NS}}$} \\
\hline & Absent & $59(66)$ & $56(62)$ & $54(60)$ & 0 & \\
\hline
\end{tabular}

NS=non-significant

With regard to other demographic variables like age, education, age of onset of drug abuse, amount of drug consumed, duration of substance abuse, and socio-economic status the means and SDs were calculated and are given in TABLE 2. For checking the significance of the difference in means of different group viz. persistent cannabis users, casual users, abstainers and healthy controls, analysis of variance was done, and results are given in TABLE 2 to TABLE 3. 
TABLE 2. Mean and SD with Duncan's post hoc analysis for demographic details, and cognitive task.

\begin{tabular}{|c|c|c|c|c|c|c|c|c|}
\hline \multirow[t]{2}{*}{ Variables } & \multicolumn{2}{|c|}{$\begin{array}{c}\text { Persistent users } \\
(\mathrm{n}=90)\end{array}$} & \multicolumn{2}{|c|}{$\begin{array}{c}\text { Casual users } \\
(n=90)\end{array}$} & \multicolumn{2}{|c|}{ Abstainers $(n=90)$} & \multicolumn{2}{|c|}{$\begin{array}{l}\text { Healthy Control } \\
(\mathrm{n}=90)\end{array}$} \\
\hline & Mean & $\mathrm{SD}$ & Mean & SD & Mean & SD & Mean & SD \\
\hline Age & 29.61 & 7.42 & 30.17 & 6.9 & 29.72 & 6.7 & 27.74 & 5.16 \\
\hline $\begin{array}{l}\text { Age of onset of } 1^{\text {st }} \\
\text { substance abuse }\end{array}$ & 20.52 & 6.28 & 21.21 & 5.51 & 21.12 & 5.33 & 0 & 0 \\
\hline $\begin{array}{c}\text { Duration of } \\
\text { substance abuse }\end{array}$ & 7.36 & 4.88 & 7.83 & 5.05 & 7.83 & 4.91 & 0 & 0 \\
\hline $\begin{array}{c}\text { Number of drugs } \\
\text { (biddi or } \\
\text { cigarette/day) }\end{array}$ & 9.58 & 4.69 & 8.68 & 6.08 & 10.8 & 7.26 & 0 & 0 \\
\hline $\begin{array}{c}\text { Socio Economic } \\
\text { Status }\end{array}$ & 76.83 & 15.17 & 81 & 13.65 & 84.81 & 13.22 & 82.2 & 12.7 \\
\hline
\end{tabular}

Results (TABLE 3) reveal that the mean age of all the groups was almost similar and the difference was non-significant $(\mathrm{F}=0.91$, $\mathrm{df}=3,356, \mathrm{p}<0.05)$. Similarly, the onset of first use of cannabis, duration of substance abuse, the amount of cannabis consumed also did not differ in the persistent, casual users of cannabis and abstainers (TABLE 3). Socio-economic status of the participants was almost similar and the mean scores of the persistent, casual users of cannabis, abstainers and the healthy control group did not differ significantly.

TABLE 3. Summary of One-way ANOVA in demographic variables.

\begin{tabular}{|c|c|c|c|c|c|}
\hline Variables & $\begin{array}{c}\text { Sources } \\
\text { of } \\
\text { Variance }\end{array}$ & SS & df & MS & F value \\
\hline \multirow[t]{2}{*}{ Age } & $\mathrm{B}_{\mathrm{SS}}$ & 118.48 & 3 & 39.49 & \multirow[t]{2}{*}{$0.91^{\mathrm{NS}}$} \\
\hline & $\mathrm{W}_{\mathrm{SS}}$ & 15387 & 356 & 43.22 & \\
\hline \multirow[t]{2}{*}{ Age of onset of $1^{\text {st }}$ substance abuse } & $\mathrm{B}_{\mathrm{SS}}$ & 2.29 & 2 & 1.14 & \multirow[t]{2}{*}{$0.05^{\mathrm{NS}}$} \\
\hline & $\mathrm{W}_{\mathrm{SS}}$ & 5973.9 & 267 & 22.37 & \\
\hline \multirow[t]{2}{*}{ Duration of substance abuse } & $\mathrm{B}_{\mathrm{SS}}$ & 26.34 & 2 & 13.17 & \multirow[t]{2}{*}{$0.55^{\mathrm{NS}}$} \\
\hline & $\mathrm{W}_{\mathrm{SS}}$ & 6390.4 & 267 & 23.93 & \\
\hline Amount of substance & $\mathrm{B}_{\mathrm{SS}}$ & 133.79 & 2 & 66.89 & \multirow[t]{2}{*}{$2.446^{\mathrm{NS}}$} \\
\hline (biddi/cigarette per day) & $\mathrm{W}_{\mathrm{SS}}$ & 7302.2 & 267 & 27.35 & \\
\hline \multirow[t]{2}{*}{ Socio Economic Status } & $\mathrm{B}_{\mathrm{SS}}$ & 919.61 & 3 & 306.54 & \multirow[t]{2}{*}{$1.76^{\mathrm{NS}}$} \\
\hline & $\mathrm{W}_{\mathrm{SS}}$ & 62049 & 356 & 174.29 & \\
\hline
\end{tabular}

Stroop Task measures the speed of processing in the brain, perseveration, flexibility and cognitive interference. In the 1stcondition, i.e., colour task, persistent users scored a mean (SD) value of 75.60 (13.72), mean score (SD) of casual users was 75.80 (15.94), mean score of abstainers was 76.72 (16.62), and healthy controls the mean (SD) value was 58.80 (12). It was found that the mean score differed significantly ( $\mathrm{F}$ value, 31.02; $\mathrm{df}=3,356 ; \mathrm{p}<0.01$ ). Post hoc analysis for significant group comparison revealed (TABLE 4) that persistent, casual and abstainers' group did not differ among themselves, however, all of these differed significantly from healthy controls. In the colour-word task, mean (SD) of persistent users was 60.67(25.35), mean (SD) of casual users 64.48 (25.05), mean (SD) of the abstainer group 73.20 (21.64), and healthy controls mean (SD) score was 91.71(15.27). The F value was 36.17; $\mathrm{df}=3,356 ; \mathrm{p}<0.01$, indicates that all groups differ from each other and post hoc analysis shows that persistent users and casual users did not differ from each other, but abstainer group varied from other groups as well as from healthy control group. 
www.yumedtext.com | April-2021 | ISSN: 2582-3264 | https://dx.doi.org/10.46527/2582-3264.134

TABLE 4. Mean and SD with Duncan's post hoc analysis for cognitive interference variables.

\begin{tabular}{|c|c|c|c|c|c|c|c|c|c|}
\hline \multirow{3}{*}{\multicolumn{2}{|c|}{ Variables }} & \multirow{2}{*}{\multicolumn{2}{|c|}{$\begin{array}{l}\text { Persistent users } \\
\quad(n=90)\end{array}$}} & \multirow{2}{*}{\multicolumn{2}{|c|}{$\begin{array}{c}\text { Casual users } \\
(n=90)\end{array}$}} & \multirow{2}{*}{\multicolumn{2}{|c|}{$\begin{array}{c}\text { Abstainers } \\
(n=90)\end{array}$}} & \multirow{2}{*}{\multicolumn{2}{|c|}{$\begin{array}{l}\text { Healthy Control } \\
\qquad(\mathrm{n}=90)\end{array}$}} \\
\hline & & & & & & & & & \\
\hline & & Mean & SD & Mean & SD & Mean & $\mathrm{SD}$ & Mean & SD \\
\hline \multirow[t]{2}{*}{$\begin{array}{c}\text { Stroop } \\
\text { Task }\end{array}$} & $\begin{array}{l}\text { Color } \\
\text { task }\end{array}$ & $75.60^{\mathrm{a}}$ & 13.72 & $75.80^{a}$ & 15.94 & $76.72^{a}$ & 16.62 & $58.80^{\mathrm{b}}$ & 11.97 \\
\hline & $\begin{array}{c}\text { Color } \\
\text { Word } \\
\text { task }\end{array}$ & $60.67^{a}$ & 25.35 & $64.48^{\mathrm{a}}$ & 25.05 & $73.20^{b}$ & 21.64 & $91.71^{\mathrm{c}}$ & 15.27 \\
\hline \multicolumn{2}{|c|}{$\begin{array}{c}\text { Dispersion } \\
\text { Quotient }\end{array}$} & $47.22^{\mathrm{a}}$ & 22.33 & $42.85^{\mathrm{a}}$ & 22.14 & $34.31^{\mathrm{b}}$ & 19.48 & $18.36^{\mathrm{c}}$ & 13.72 \\
\hline
\end{tabular}

Superscript a, b, c \& d alphabet indicates the significance between groups. Similar alphabet indicates the non-significant, whereas dissimilar alphabet indicates the significant difference.

Dispersion Quotient of the persistent users mean (SD) value was 47.22 (22.33), for the casual users it was 42.85 (22.14), for abstainers it was 34.31 (19.48), and for healthy controls mean (SD) was 19.48 (18.36). F value was 37.50, df=3,356; p<0.01, which shows that the means differed significantly. The higher the mean value indicates more the cognitive interference of the brain. A careful perusal of the results indicates that persistent users and casual users showed more deficits in cognitive functions on this task and also had more cognitive interference than healthy control and abstainers. The results of the study agree with those of Auer et al [21] reporting the adverse effect of cannabis use on verbal memory and processing. Similarly, Krista et al.,[12] reported that cannabis exposure was associated with poor psychomotor performance, sustained attention, and cognitive inhibition. Horwood et al.,[22] and Huestegge et al.,[23] also reported an adverse effect of cannabis use on cognitive functions.

TABLE 5. Summary of One-way ANOVA in cognitive interference variables.

\begin{tabular}{|c|c|c|c|c|c|}
\hline \multicolumn{2}{|c|}{ Variables } & \multirow{2}{*}{$\begin{array}{c}\begin{array}{c}\text { Sources of } \\
\text { Variance }\end{array} \\
\mathrm{B}_{\mathrm{SS}}\end{array}$} & \multirow{2}{*}{$\begin{array}{c}\text { SS } \\
20051\end{array}$} & \multirow{2}{*}{$\begin{array}{c}\text { MS } \\
6683.6\end{array}$} & \multirow{2}{*}{$\begin{array}{c}\mathbf{F} \\
31.02 * *\end{array}$} \\
\hline \multirow[t]{4}{*}{ Stroop Task } & \multirow{2}{*}{$\begin{array}{c}\text { Color } \\
\text { task }\end{array}$} & & & & \\
\hline & & $\mathrm{W}_{\mathrm{SS}}$ & 76711 & 215.48 & \\
\hline & \multirow{2}{*}{$\begin{array}{l}\text { Color } \\
\text { Word }\end{array}$} & $\mathrm{B}_{\mathrm{SS}}$ & 52310 & 17437 & \multirow[t]{2}{*}{36.17 ** } \\
\hline & & $\mathrm{W}_{\mathrm{SS}}$ & 171602 & 482.03 & \\
\hline \multirow{2}{*}{\multicolumn{2}{|c|}{ Dispersion Quotient }} & $\mathrm{B}_{\mathrm{SS}}$ & 43782 & 14594 & \multirow[t]{2}{*}{$37.5 * *$} \\
\hline & & $\mathrm{W}_{\mathrm{SS}}$ & 138558 & 389.21 & \\
\hline
\end{tabular}

$*=$ significance level at $0.05 ; * *=$ significance level at 0.01

Wisconsin Card Sorting Test is a measure of higher cognitive functions. It was administered to all the participants uniformly and trial, correct responses, \% error responses, \% Preservative responses, \% Preservative errors, \% Non-Preservative errors, \%Conceptual Level Response, Total Trial to Complete First Category, Failure to Maintain Set, and Learning to Learn were taken as measures of executive functions. The mean scores along with SD for all the above measures are given in TABLE 6. For significant difference among these means of persistent, casual users of cannabis, abstainers and healthy controls group One Way ANOVA was done and results are given in TABLE 7. For significant group comparisons Post hoc (Duncan's) test was done and the results are given in TABLE 6. 
TABLE 6. Mean and SD with Duncan's post hoc analysis for Wisconsin Card Sorting Test.

\begin{tabular}{|c|c|c|c|c|c|c|c|c|}
\hline \multirow[t]{2}{*}{ Variables } & \multicolumn{2}{|c|}{$\begin{array}{c}\text { Persistent users } \\
(\mathbf{n}=90)\end{array}$} & \multicolumn{2}{|c|}{$\begin{array}{c}\text { Casual users } \\
(\mathbf{n}=90)\end{array}$} & \multicolumn{2}{|c|}{$\begin{array}{c}\text { Abstainers } \\
(\mathbf{n}=90)\end{array}$} & \multicolumn{2}{|c|}{$\begin{array}{c}\text { Healthy Control } \\
(\mathbf{n}=90)\end{array}$} \\
\hline & Mean & SD & Mean & SD & Mean & SD & Mean & SD \\
\hline Trial & $128.0^{\mathrm{a}}$ & 0 & $127.71^{\mathrm{a}}$ & 1.71 & $126.16^{\mathrm{a}}$ & 7.53 & $111.78^{b}$ & 18.84 \\
\hline $\begin{array}{c}\text { Correct } \\
\text { Responses }\end{array}$ & $56.62^{\mathrm{a}}$ & 11.12 & $59.32^{\mathrm{a}}$ & 12.66 & $63.02^{\mathrm{b}}$ & 14.36 & $73.06^{c}$ & 9.88 \\
\hline \%Errors & $33.91^{\mathrm{a}}$ & 5.5 & $34.58^{\mathrm{a}}$ & 5 & $36.22^{\mathrm{a}}$ & 6.25 & $44.34^{b}$ & 7.33 \\
\hline \%P Responses & $42.54^{\mathrm{a}}$ & 7.91 & $30.82^{\mathrm{b}}$ & 5.61 & $33.58^{\mathrm{c}}$ & 8.03 & $30.82^{b}$ & 5.27 \\
\hline \%P Errors & $64.02^{\mathrm{a}}$ & 14.52 & $63.30^{\mathrm{b}}$ & 14.54 & $61.80^{\mathrm{b}}$ & 15.05 & $55.59^{\mathrm{b}}$ & 15.83 \\
\hline $\begin{array}{c}\text { \%Non-P } \\
\text { Errors }\end{array}$ & $49.64^{\mathrm{a}}$ & 9.28 & $48.03^{\mathrm{a}}$ & 7.48 & $48.10^{\mathrm{a}}$ & 6.18 & $45.33^{b}$ & 8.06 \\
\hline \%CLR & $34.33^{\mathrm{a}}$ & 5.27 & $35.69^{\mathrm{ab}}$ & 6.39 & $37.41^{\mathrm{b}}$ & 7.15 & $42.81^{\mathrm{c}}$ & 6.53 \\
\hline NOCC & $22.14^{\mathrm{a}}$ & 12.17 & $25.41^{\mathrm{ab}}$ & 12.73 & $30.44^{\mathrm{bc}}$ & 13.34 & $75.96^{\mathrm{d}}$ & 26.82 \\
\hline TTCFC & $37.52^{\mathrm{ab}}$ & 27.3 & $33.23^{\mathrm{bc}}$ & 23.14 & $34.87^{\mathrm{bc}}$ & 23.21 & $26.84^{\mathrm{bc}}$ & 20.49 \\
\hline FTMS & $51.72^{\mathrm{a}}$ & 41.73 & $22.59^{\mathrm{b}}$ & 22.31 & $21.43^{\mathrm{b}}$ & 31.29 & $16.98^{\mathrm{b}}$ & 21.93 \\
\hline $\mathbf{L L}$ & $10.07^{\mathrm{a}}$ & 14.55 & $15.66^{\mathrm{a}}$ & 20.19 & $23.45^{\mathrm{b}}$ & 24.46 & $65.01^{\mathrm{c}}$ & 35.09 \\
\hline
\end{tabular}

Superscript a, b, c \& d alphabet indicates the significance between groups. Similar alphabet indicates the non-significant, whereas dissimilar alphabet indicates the significant difference.

A careful perusal of the results given in TABLE 6 and 7, reveal that four groups differ significantly on all measures of WCST excepting Trial to Complete First Category (TABLE 7). In case of total trial to complete the entire test, all the groups i.e. persistent and casual users of cannabis, abstainers and healthy controls differ significantly ( $\mathrm{F}=52.78, \mathrm{df}=3,356, \mathrm{p}<0.01)$. Post hoc Duncan's analysis reveal that the healthy control group took significantly less number of trials as compare to other three groups (i.e. persistent, casual \& abstainers). Similar results were found in case of number of errors, non-preservative errors (TABLE $6 \& 7$ ).

TABLE 7. Summary of One-way ANOVA for Wisconsin Card Sorting test $(\mathbf{d f}=\mathbf{3} ; \mathbf{3 5 6})$.

\begin{tabular}{|c|c|c|c|c|}
\hline Variables & $\begin{array}{c}\text { Sources of } \\
\text { Variance }\end{array}$ & SS & MS & F value \\
\hline \multirow[t]{2}{*}{ Trial } & $\mathrm{B}_{\mathrm{SS}}$ & 16417 & 5472.4 & \multirow[t]{2}{*}{$52.78^{* *}$} \\
\hline & $\mathrm{W}_{\mathrm{SS}}$ & 36912 & 103.69 & \\
\hline \multirow[t]{2}{*}{ Correct Responses } & $\mathrm{B}_{\mathrm{SS}}$ & 13979 & 4659.5 & \multirow[t]{2}{*}{$31.72 * *$} \\
\hline & $\mathrm{W}_{\mathrm{SS}}$ & 52299 & 146.91 & \\
\hline \multirow[t]{2}{*}{ \%Error } & $\mathrm{B}_{\mathrm{SS}}$ & 5410.9 & 1803.6 & \multirow[t]{2}{*}{$4.72 * *$} \\
\hline & $\mathrm{W}_{\mathrm{SS}}$ & 136007 & 382.04 & \\
\hline \multirow[t]{2}{*}{ \%P Responses } & $\mathrm{B}_{\mathrm{SS}}$ & 8334.2 & 2778.1 & \multirow[t]{2}{*}{$59.65^{* *}$} \\
\hline & $\mathrm{W}_{\mathrm{SS}}$ & 16581 & 46.57 & \\
\hline \multirow[t]{2}{*}{ \%P Errors } & $\mathrm{B}_{\mathrm{SS}}$ & 3979.6 & 1326.5 & \multirow[t]{2}{*}{$5.90 * *$} \\
\hline & $\mathrm{W}_{\mathrm{SS}}$ & 80061 & 224.89 & \\
\hline \multirow[t]{2}{*}{ \%Non-P Errors } & $\mathrm{B}_{\mathrm{SS}}$ & 866.6 & 288.87 & \multirow[t]{2}{*}{$4.71 * *$} \\
\hline & $\mathrm{W}_{\mathrm{SS}}$ & 21826 & 61.31 & \\
\hline \multirow[t]{2}{*}{ \% CLR } & $\mathrm{B}_{\mathrm{SS}}$ & 3735.8 & 1245.3 & \multirow[t]{2}{*}{$30.70^{* *}$} \\
\hline & $\mathrm{W}_{\mathrm{SS}}$ & 14441 & 40.56 & \\
\hline \multirow[t]{2}{*}{ NOCC } & $\mathrm{B}_{S S}$ & 141500 & 47167 & \multirow[t]{2}{*}{$156.27 * *$} \\
\hline & $\mathrm{W}_{\mathrm{SS}}$ & 107451 & 301.83 & \\
\hline \multirow[t]{2}{*}{ TTCFC } & $\mathrm{B}_{\mathrm{SS}}$ & 5402 & 1800.7 & \multirow[t]{2}{*}{$2.23^{\mathrm{NS}}$} \\
\hline & $\mathrm{W}_{\mathrm{SS}}$ & 287743 & 808.27 & \\
\hline \multirow[t]{2}{*}{ FTMS } & $\mathrm{B}_{\mathrm{SS}}$ & 68086 & 22695 & \multirow[t]{2}{*}{$19.43 * *$} \\
\hline & $\mathrm{W}_{\mathrm{SS}}$ & 415771 & 1167.9 & \\
\hline \multirow[t]{2}{*}{$\mathbf{L L}$} & $\mathrm{B}_{\mathrm{SS}}$ & 167650 & 55883 & \multirow[t]{2}{*}{$91.29 * *$} \\
\hline & $\mathrm{W}_{\mathrm{SS}}$ & 217920 & 612.13 & \\
\hline
\end{tabular}

$* *=$ significance level at $0.01, \mathrm{NS}=$ non-significant 
In case of number of correct responses all the groups differ significantly $(\mathrm{F}=31.72, \mathrm{df}=3,356, \mathrm{p}<0.01)$ TABLE 7 . Post hoc comparison revealed that the healthy group scored maximum correct responses which were significantly higher than all three groups. The abstainers also scored higher than both the persistent and casual users. The participants and casual users did not differ from each other (TABLE 6). Similar results were obtained in case of preservative response. Results reported by Ramaekers et al. [10], indicating impairment in decision making and increasing reaction time and impaired the executive functions are similar to the results of the present findings. In case of preservative error, the F value is 5.90 which is significant at 0.01 level (TABLE 4.9). Post hoc comparison reveals that preservative error was more in healthy controls followed by abstainers, casual users and persistent users. So, the persistent users committed more preservative errors.

On number of category completed, the F value is $156.27(\mathrm{df}=3,356)$ which is significant at 0.01 level (TABLE 4.9). Post hoc comparison reveals that healthy groups completed more category followed by abstainers, casual users and persistent users. The cannabis users did not differ from each other, but they all differ from healthy controls (TABLE 6). On conceptual level response the means scores of four groups differed significantly. Post hoc comparison reveals that the highest score obtained by the healthy controls differed significantly from all the three groups. The persistent cannabis users scored significantly less than the abstainers and healthy controls. In case of failure to maintain set the mean scores differed significantly $(\mathrm{F}=19.43$, $\mathrm{df}=3,356$, $\mathrm{p}<0.01)$. Post hoc comparison reveals that the persistent users scored significantly higher on FTMS compared to casual users, abstainers and healthy controls.

On learning to learn again all groups differed significantly (TABLE 7). Post hoc comparisons reveal that the healthy controls groups scored significantly higher than persistent and casual users of cannabis. The persistent and casual users did not differ among themselves (TABLE 6). Some studies from review of literature suggest that use of cannabis effect on overall/global cognition and executive functions [5-7]. Ramaekers et al. [10] reported significant negative effects of use of cannabis EF, impulse control, attention and psychomotor functions. Results of our study also support the results of all these previous studies in term of adverse effect of cannabis on executive functions.

\section{Limitations}

The present study has several limitations which need to account. The education variable in healthy control group was not controlled. The premorbid cognitive functions of the participants were not recorded. All the participants were age ranged between 18 years to 40 years and therefore the result may be not applicable to adolescents. Only male participants were taken, and therefore further research need to be focused on identifying the effect in female users and gender difference.

\section{Implication and Future Direction}

Future researchers should be planned for longitudinal study in context of cause effect relationship of cannabis and executive functions. Large sample with varied age range could be taken so that better generalization could be possible. In the present research only, quantitative account has been taken, hence future research may take qualitative account as well to magnify the effect of age of onset of substance abuse, duration of substance abuse, and gender on effect of cannabis and executive functions. To get the microscopic information demographic information like education, and diverse occupation etc. could be considered by the future researchers. The present study provides a direction for mental health practitioners for planned a better program to 
www.yumedtext.com | April-2021 | ISSN: 2582-3264 | https://dx.doi.org/10.46527/2582-3264.134

improve the executive functions of substance users, especially cannabis users through psychological intervention or other treatment.

\section{Conclusion}

In the light of present study, it has been finding out that the use of cannabis had adverse effect on executive functions. Moreover, the data suggests associations between abstinence and improved executive functions. The results of the present study also highlight that after abstinence there is significant improvement in executive functions, i.e., response inhibition, problem solving, decision making speed of brain and flexibility etc.

\section{Declaration Section}

Ethical Approval and Consent to participate: The present study was a part of research work conducted for the award of Doctorate of Philosophy Degree to the author. The proposal (ID= IGR-07-IGR-1471) was cleared by statutory bodies of the university (Maharshi Dayanand University, Rohtak, Haryana, India). Inform consent was taken from each and every participant besides seeking permission from the centers.

- Consent for publication: Yes

- Availability of supporting data: Yes

- Competing interests: Nil

- Funding: Not funding

- Authors' contributions: Not applicable

- Acknowledgements: The author is heartily thankful to all participants and the owner of the hospital who allowed for data collection.

\section{REFERENCES}

1. Malenka RC, Nestler EJ, Hyman SE. Chapter 13: Higher Cognitive Function and Behavioral Control. In: Sydor, A, Brown RY, editors. Molecular Neuropharmacology: A Foundation for Clinical Neuroscience. 2nd ed. New York: McGraw-Hill Medical, USA; 2009. 315 p.

2. Diamond A. Executive functions. Annu Rev Psychol. 2013;64:135-68.

3. Chan RC, Shum D, Toulopoulou T, et al. Assessment of executive functions: review of instruments and identification of critical issues. Arch Clin Neuropsychol. 2008;23(2):201-16.

4. Alvarez JA, Emory E. Executive function \& the frontal lobes: A meta-analytic review. Neuropsychol Rev. 2006;16(1):17-42.

5. Cohen K, Weinstein AM. Synthetic and Non-synthetic Cannabinoid Drugs and Their Adverse Effects-A Review From Public Health Prospective. Front Public Health. 2018;6:162.

6. Gonzalez-Pinto A, Gonzalez-Ortega I, Alberich S, et al. Opposite Cannabis-Cognition Associations in Psychotic Patients Depending on Family History. PLoS ONE. 2016;11(8):e0160949.

7. Verdejo-Garcia A, Rivas-Perez C, Lopez-Torrecillas F, et al. Differential impact of severity of drug use on frontal behavioral symptoms. Addict Behav. 2006;31(8):1373-82.

8. Ramaekers JG, van Wel JH, Spronk D, et al. Cannabis and cocaine decrease cognitive impulse control and functional corticostriatal connectivity in drug users with low activity DBH genotypes. Brain Imaging Behav. 2016;10(4):1254-63.

9. Raul G, Randi MS, Robin JM, et al. Performance of Young Adult Cannabis Users on Neurocognitive Measures of Impulsive Behavior and their Relationship to Symptoms of Cannabis Use Disorders. J Clin Exp Neuropsychol. 2012;34(9): 962-76. 
10. Ramaekers JG, Kauert G, van Ruitenbeek P, et al. High-potency marijuana impairs executive function and inhibitory motor control. Neuropsychopharmacology. 2006;31(10):2296-303.

11. Krista ML, Natasha EW, Christopher KM, et al. Considering Cannabis: The Effects of Regular Cannabis Use on Neurocognition in Adolescents and Young Adults. Curr Addict Rep. 2014;1(2):144-56.

12. Grant JE, Chamberlain SR, Schreiber L, et al. Neuropsychological deficits associated with cannabis use in young adults. Drug Alcohol Depend. 2012;121(1-2):159-62.

13. Hunault CC, Mensinga TT, Bocker KB, et al. Cognitive and psychomotor effects in males after smoking a combination of tobacco and cannabis containing up to $69 \mathrm{mg}$ delta-9-tetrahydrocannabinol (THC). Psychopharmacology (Berl). 2009;204(1):85-94.

14. Verdejo-Garcia AJ, Lopez-Torrecillas F, Aguilar de Arcos F, et al. Differential effects of MDMA, cocaine, and cannabis use severity on distinctive components of the executive functions in poly-substance users: a multiple regression analysis. Addict Behavior. 2005;30(1):89-101.

15. Hartman RL, Huestis MA. Cannabis effects on driving skills. Clinical Chemistry 2013;59(3):478-92.

16. Bartholomew J, Holroyad S, Hefferman TM. Does cannabis use affect prospective memory in young adults? J Psychopharmacol. 2010;24(2):241-6.

17. Singh R, Shyam R, Kumar S. Socio Economic Status Scale. National Psychological Corporation. Kachehri Ghat, Agra, India. 2007.

18. Stroop JR. Studies of interference in serial verbal reactions. J Exp Psychol. 1935;18(6):643-62.

19. Stroop JR. Factors affecting speed in serial verbal reactions. Psychol Monogr. 1938;50(5):38-48.

20. Berg EA. A simple objective technique for measuring flexibility in Thinking. J Gen Psychol. 1948;39:15-22.

21. Auer R, Vittinghoff E, Yaffe K, et al. Association between Lifetime Marijuana use and Cognitive Function in Middle Age: The Coronary Artery Risk Development in Young Adults (CARDIA) Study. JAMA Intern Med. 2016;176(3):352-61.

22. Horwood LJ, Fergusson DM, Hayatbakhsh MR, et al. Cannabis use and educational achievement: findings from three Australasian cohort studies. Drug Alcohol Depend. 2010;110(3):247-53.

23. Huguelet P, Zanello A, Nicastro R. A study of visual and auditory verbal working memory in schizophrenic patients compared to healthy subjects. Eur Arch Psychiatry Clin Neurosci. 2000;250(2):79-85. 